\title{
MICROCLIMATES OF L'AVEN D'ORGNAC AND OTHER FRENCH LIMESTONE CAVES (CHAUVET, ESPARROS, MARSOULAS).
}

\section{MICROCLIMATES OF L'AVEN D'ORGNAC. (Short title)}

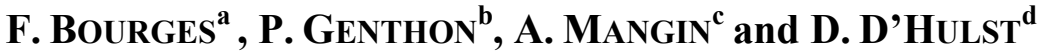 \\ ${ }^{a}$ Géologie-Environnement-Conseil, 30 rue de la République, 09200 St Girons, France, \\ email : geconseil@wanadoo.fr. \\ ${ }^{\mathrm{b}}$ IRD Paléotropique, Nouméa, Nouvelle Calédonie, email : \\ pierre.genthon@noumea.ird.nc. \\ ${ }^{c}$ LEH, Laboratoire de Moulis, 09200 St Girons, France, email : \\ alain.mangin@1sm.cnrs.fr \\ ${ }^{\mathrm{d}}$ FRET, Laboratoire de Moulis, 09200 St Girons, France, email : \\ dominique.dhulst@1sm.cnrs.fr
}




\begin{abstract}
We assess the aerodynamics of some limestone cave atmospheres, using a 5 year monitoring of Aven d'Orgnac system, shorter thermal vertical profiling experiments, and comparison with time series from other French caves. In the first rooms, located under the Aven opening, our records indicate, each year, the succession of a summer regime characterized by stable parameters, except for the perturbations introduced by tourist visits, and a winter regime, where the inner air temperature drops and is highly correlated with the one outside. Atmospheric composition suggests that during the winter regime the cave is ventilated by outside air. We show that the onset of the winter regime is governed by a thermoconvective instability involving the inflow of the outside cold and dense air. Atmospheric temperature and composition allow to follow the stepwise progression of the winter regime toward the adjacent rooms.

In the Salle Plane, a far room of the Orgnac-Issirac karstic system, where the winter regime has never been observed, the air temperature is extremely homogeneous, steady, and characterized a less than $0.03{ }^{\circ} \mathrm{C}$ amplitude half-daily signal that is correlated with the derivative of pressure versus time. This correlation, which is also observed in various confined caves, may be explained by pressure-induced temperature changes relaxed in less than one hour by thermal exchanges with a large rock volume whose temperature is assumed to be constant.

The various microlimates of a karstic cave system should be taken into account for the conservation of caves open to tourists and for the interpretation of growth laminae of speleothems.
\end{abstract}


KEYWORDS : cave; cave management; microclimate; thermoconvection; confinement; physical mechanism; France.

\section{INTRODUCTION}

The stability of cave climates is associated with the exceptional conservative properties of their environment. Detritic and chemical deposits which contain accurate continental paleoenvironmental records and major archaeological testimonies, including the oldest human artistic expressions, have sometimes been miraculously preserved in caves.

Most underground atmospheres of caves are very stable in temperature and composition. Yet, the mechanisms involved in this stability and their robustness througouht the time remain open to discussion in different issues pertaining to caves and painted caves conservation (Andrieux, 1970; Fernandez et al., 1986; De Freitas and Littlejohn, 1987; Cigna, 1993; Hoyos et al. 1997; Mangin and D'Hulst, 1996; PulidoBosh et al., 1997; Mangin et al., 1999), and to interpretation of paleoclimates deduced from cave sediments or speleothems analysis (Genty, 1993; Genty et al., 2001; Sondag et al., 2003; Soubies et al., 2005). The wide variety of natural conditions depicted in the abundant speleologic literature (Trombe, 1952; Saar, 1954; Geiger, 1959; Renault, 1961; Conn, 1966; Ciry, 1967; Cigna, 1967, Schoeller, 1967; Eraso, 1971) suggests that several physical mechanisms may be involved in the regulation of cave atmospheres. Recently, Perrier et al. $(2001,2004)$ have proposed and quantified a series of physical mechanisms from thermal and compositional data gathered in an abandoned underground limestone quarry. 
Due to several initial discontinuities enlarged by dissolution, the caves of karstic systems exchange gases and water with the outside medium through various sized channels and thus might behave differently than quarries. Small size voids will be termed macrofissural or microfissural according to Mangin (1995). The macrofissural network consists of dissolution voids following the initial discontinuities (e.g. fractures, fissures, or joints) and characterized by a millimetric to centimetric aperture. This network is either clogged by sediments, especially in a multilevel karstic system, or open, ensuring fast transfer of gas between the underground rooms and the outside atmosphere and also the seeping of meteoric water during strong rainy events. In contrast, the microfissural network is constituted by the initial fissure system with less than $1 \mathrm{~mm}$ aperture. Due to interfacial tension and to its narrow opening, this microfissural system is submitted to biphasic flow and allows the downward transfer of both rainwater and $\mathrm{CO}_{2}$ rich air from the soil toward the different caves and to the aquifer. Thus, the size of the natural system is much larger than the cave volume, whereas the different levels of energy and fluxes depend on the type and the location of voids in the karstic system and also on highly variable local surface conditions. This led our team first to a systemic approach based on the analysis of matter and energy fluxes (Mangin, 1984; Mangin, 1995). Besides, monitoring the temperature and the composition of natural cave atmosphere can provide some hints on the physical processes in action.

The present work is based on a long-term environmental survey in the Aven d'Orgnac (France) and on short experimentations in the Orgnac-Issirac cave network. It has been largely coupled with similar monitoring operations in the neighboring prehistoric 
painted cave Grotte Chauvet ( $7 \mathrm{~km}$ to the North East) and with other sites of patrimonial interest in the French Pyrenees (Gouffre d'Esparros, Grotte de Marsoulas).

In the Aven d'Orgnac, investigations on the origin and the evolution of the underground atmosphere (total gas analysis, $\mathrm{C}$ isotopes data, $\mathrm{CO}_{2}$ concentrations time series and profiles) led us (Bourges et al., 2001, hereafter referred to as BMH01), to identify the annual succession of two contrasting aerodynamic regimes, roughly synchronous with outside seasons. In the summer regime, the $\mathrm{CO}_{2}$ concentration is nearly constant and equal to $1.8 \%$ in the whole cave system. It was proposed that the $\mathrm{CO}_{2}$ produced in soil was advected continuously downwards through the microfissural network and released in the cave atmosphere through its walls. $\mathrm{CO}_{2}$ production estimates from atmospheric compositional analysis of the confined rooms of the cave system and from coupled compositional and air flow measurements at natural openings in summer have indicated that the mean production of the Aven was about 2 tons of pure $\mathrm{CO}_{2}$ per day and that $\mathrm{CO}_{2}$ rich air escaped the cavity at a rate of 60000 to $160000 \mathrm{~m}^{3} /$ day. In the winter regime however, several emptying events were observed, characterized by a sudden drop of $\mathrm{CO}_{2}$ concentration, beginning near the entrance of the cave and propagating stepwise toward its deeper parts, resulting a steep $\mathrm{CO}_{2}$ increase at the entrance of the first cave room which is still governed by the summer regime. This was interpreted as the consequence of an efficient ventilation with outside air entering the cave at a mean rate estimated at 100000 to $500000 \mathrm{~m}^{3} /$ day, resulting in a strong dilution of the underground atmosphere. Changes in space and in time of the cave atmosphere composition led us to suggest that aerodynamic transfer was a major process in the karst system dynamics which could have an impact on calcite deposition. However, thermal patterns supporting this dynamics remain largely misunderstood. The present paper 
focusses on the thermo-aerodynamics of the Aven d'Orgnac, using 5 years of continuous thermal records in different parts of the cave system, recent thermal and compositional surveys in the upper zone, and 3 vertical temperature profiles gathered at the cave entrance and in the far cave system. The interpretation of the continuous thermal survey is first presented. Then, we discuss the thermoconvective state of the different cave rooms, using vertical temperature profiles as well as $\mathrm{CO}_{2}$, relative humidity and ${ }^{222} \mathrm{Rn}$ records. Physical mechanisms controlling daily to hourly air temperature changes are also discussed. Finally, infererences are drawn about the growth of speleothems and on the management of cave environment in order to conserve prehistoric cave paintings.

\section{THE AVEN D'ORGNAC STUDY AREA}

The Aven d'Orgnac (aven is an old celtic word for a natural opening connected by a vertical shaft to an underground cave system) and the Orgnac-Issirac underground network constitute a tourist cave, $2 / 3$ of which is open to speleological tours, while the other part benefits from an integral protection as a "natural monument". The title "Grand Site de France" given by the French Ministry of Environment in 2004 testifies that its management is compatible with environmental standards of sustainable development.

The Est Central Massif, on the right bank of the Rhone valley, includes limestone plateaus formed by Mesozoic sediments filling the Rhone Graben, while Cenozoic deposits are located in tectonic depressions of the nearby Alès trench and Issirac basin. The limestone formations have recorded the nearby Pyrenean and Alpine deformations that resulted in large scale folding and fractures observed at different scales with the 
N20 dominant direction. Between the Ardèche and the Cèze river gorges, Orgnac caves develop in a wide antiform of Lower Aptian reef limestone of Urgonian facies. The Aven d'Orgnac opens onto a $300 \mathrm{~m}$ altitude plateau with a $15 \mathrm{~m}$ vertical pit, $4.7 \times 2 \mathrm{~m}$ wide in its narrowest cross section (figure 1b). The pit leads to the top of a room called Salle De Joly (termed SDJ hereafter), $35 \mathrm{~m}$ high and more than $90 \mathrm{~m}$ wide, presenting spectacular speleothems. A wide downsloping gallery including the Grand Chaos zone (GC) gives access to another part of the cave extending mainly to the $120 \mathrm{~m}$ topographic level "Les Salles Rouges" (termed SR), that consists in a succession of large rooms with extensive clay fillings and huge speleothems. A volume of $237000 \mathrm{~m}^{3}$ has been estimated for the directly accessible galleries of the Aven d'Orgnac cave system. However, the large voids and the cave network were only estimated to make up less than $1 \%$ of the whole rock formation volume (Mangin, 1976). SDJ is connected to the 4 $\mathrm{km}$ long Orgnac-Issirac underground network which develops northwards near the -120 $\mathrm{m}$ level (figure 1a). It is also characterized by successive rooms of very large volumes and speleothems of exceptional esthetical interest. The whole network is supposed to have been generated during tertiary times (Blanc, 1997). Then it was disconnected from the drainage network in Messinian when the Mediterranean Sea level lowered down to $-1600 \mathrm{~m}$ and was later filled by large amounts of Pliocene sediments, that have been partly removed in recent periods. Nowadays, water seepage from surface controls the main flux of fluids (water and gas) in the speleological network. The first explorations in 1935 did not locate the water level, but the centennial rain event of 2002 and new piezometric data (2003-2005) showed that a large flooded karst zone was located just under the deeper parts of the cave. It is generally assumed that the system drains in the Cèze river. 
The survey of underground conditions in the Aven d'Orgnac began at the end of 1996 when the French Ministry of Environment ordered a feasibility study of the renovation of tourist equipments in the cave in terms of environmental constraints. Specific concerns were on the long term increase of $\mathrm{CO}_{2}$ concentration in the whole cave, on the natural stability of the system, on the effects of visitors and lighting, and on the impact of a lift project including a $120 \mathrm{~m}$ pit reaching the lower cave rooms. The Aven d'Orgnac is open to tourist visits (about 110000 persons per year) down to the SR opening with a noticeable impact on the room temperature during visits due to the electrical power used for lightning.

\section{THE MONITORING SYSTEM}

The thermal monitoring device consists of an AOIP SA32 data logger connected to temperature platinum Pt100 sensors located in 5 measurement plots along the cavity (from $-45 \mathrm{~m}$ to $-135 \mathrm{~m}$ from the surface). This device has been used for a long time by our team. The absolute precision of the temperature sensors is $0.3{ }^{\circ} \mathrm{C}$, but it was largely improved, firstly by an absolute calibration of the data logger against a reference Pt 100 sensor in laboratory, and secondly by a relative calibration of the whole measurement chain in the cave. Moreover, a constant $100 \Omega$ resistance has been included in the measurement chain to control the drift of the data logger. The absolute precision of the measurements can be estimated to nearly $0.05^{\circ} \mathrm{C}$, with a relative precision of $0.01{ }^{\circ} \mathrm{C}$ and a sensitivity of $0.001{ }^{\circ} \mathrm{C}$. A chilled mirror hygrometer (General Eastern, M4-type with high precision sensors) measures the relative hygrometry with a $1 \%$ accuracy and a $0.01 \%$ resolution. The radon alpha radioactivity is obtained from a Algade, Barasol probe $\left(1 \mathrm{~Bq} / \mathrm{m}^{3}\right.$ is equivalent to a $1.77 \times 10^{-20}$ radon concentration). Two $\mathrm{CO}_{2}$ probe 
systems (Dreager Polytron IR $\mathrm{CO}_{2}$ infrared sensor) and a barometer complete this monitoring network. All data were recorded each 15 mins. A climatic station with a rain gauge, an air temperature and a pressure sensor recording at the same lag of 15 mins was set up on surface. We completed the survey with thermal experimentations and profiles in the different rooms.

Temperature has been recorded in the different rooms of the cave system (figure $1 \mathrm{~b}$ ) between 1997 and 2002. The recording was stopped for 6 months due to flooding of the different data loggers during the centennial rainy event of September 2002. The monitoring recommenced in March 2003 and continues up to date, with only three sensors, two in SDJ, one in GC. In order to define the thermal stratification inside the caves, three vertical profiles have been measured in 2002, two in SDJ between January 24 and January 25 and between August 7 and August 8, while the third one has been measured in Salle Plane, a room of the far cave system, between June 14 and June 19. The cave is open to tourists with a new equipment since June 2002. We shall firstly discuss the general thermal behavior of the system and then focus on the vertical profiles.

\section{RESULTS}

\subsection{Temperature in the first rooms (SDJ to SR)}

\subsubsection{A five year temperature record}

Figure 2 shows that all air temperatures in the cave are characterized by a marked yearly signal of amplitude decreasing away from the cave entrance, amounting to $2.1{ }^{\circ} \mathrm{C}$ in 
SDJ, to $1{ }^{\circ} \mathrm{C}$ in $\mathrm{GC}$ to $0.5{ }^{\circ} \mathrm{C}$ in Salles Rouges Balcony (SRB), and to $0.4{ }^{\circ} \mathrm{C}$ in SR, for an outside air temperature amplitude of nearly $25^{\circ} \mathrm{C}$. The yearly signal is offset with respect to the external temperature, with a flat maximum in the summer, that is poorly correlated in time with the outside temperature, and lasts almost until November. During the first winter cold nights, SDJ air temperature falls, and becomes closely correlated with the outside temperature. The frequency content of the air temperature signal recorded in the different room has been estimated by the modified correlogram method (Box et al., 1994). This method computes the spectral density, which is a measure of amplitude squared of the signal at a given frequency. SDJ air temperature presents a marked peak at $24 \mathrm{~h}$ only while the $12 \mathrm{~h}$ period is present in the other room, with an amplitude increasing away from the Aven (figure 3). This denotes that different aerodynamical regimes are in action in these different cave compartments. Figure 4a shows the transition toward the winter regime in autumn 2004. During the first cold night of October 15 , the outside temperature falls to $7^{\circ} \mathrm{C}$ with the minimum temperature remaining below $9{ }^{\circ} \mathrm{C}$ for the next two nights. This is associated with a $0.5^{\circ} \mathrm{C}$ decrease in the SDJ air temperature together with a drastic change in composition of the SDJ air, i.e. a drop in ${ }^{222} \mathrm{Rn}$ activity and in relative humidity, and a fall in $\mathrm{CO}_{2}$ concentration to almost the value outside. The return to milder outside temperatures in the following week is associated with an almost complete recovery of temperature, ${ }^{222} \mathrm{Rn}$ activity, $\mathrm{CO}_{2}$ concentration and relative humidity with a time constant of three days. This led us to consider that the SDJ atmosphere returned back to its summer composition at the end of this period. The outside temperature once again lowers under $7{ }^{\circ} \mathrm{C}$ during the night of October 25 and induces a fall in the temperatures, $\mathrm{CO}_{2}$ and ${ }^{222} \mathrm{Rn}$ activities in the cave atmosphere. In contrast to the previous situation, 
this event is only followed by a partial recovery at the end of the period, when both the minimum and maximum outside temperatures are well above that of SDJ. From November 5 , night temperatures fall gradually to near $0{ }^{\circ} \mathrm{C}$, and the winter regime establishes, propagating from SDJ to GC on November 9, and progresses stepwise toward remote rooms. It was noticed that this regime switch sets on at a higher temperature than that of October 15, and that it is correlated with the depletion of $\mathrm{CO}_{2}$ in the cave and hence, with a lower air density. The propagation toward the remote rooms of the Orgnac cave system is clearly shown in figure $4 \mathrm{~b}$ (for which, however, outside temperature data are not available).

\subsubsection{Thermal profiling in Salle de Joly}

Deeper insight into the aerodynamics of SDJ and about the winter and the summer regimes may be gained from our one day thermal profiling experiments of January and July, 2002. The top of figure 5 characterizes the summer air temperature profile. In July, the most striking feature is the increase of all temperatures during the daily tourist visits. We note, however, that the shape of the air temperature profile is qualitatively identical during the day and the night, the highest temperature being located at mid-height of the profile, with colder temperatures near the bottom and near the roof, and a slight asymmetry, with higher temperatures in the upper half of the profile. This suggests that warmer air from the remote parts of the cave flows toward the aven. Along the way, it is progressively cooled at contact by the rock walls of the passage in the lower part of the caves system that experience pronounced cooling during winter

During winter the air temperature profile is deeply changed and presents a $1{ }^{\circ} \mathrm{C}$ average temperature drop during days. During the nights, the sensors, especially the lower ones, 
are subjected to a negative perturbation of amplitude culminating to $0.3{ }^{\circ} \mathrm{C}$ at $5 \mathrm{~m}$ from the floor and that is closely correlated with that of the outside air. This may be well explained by thermal convection with the colder, denser, outer air flowing toward the bottom of the SDJ and the warmer air flowing from the cave toward the aven opening.

\subsubsection{Thermal convection during the winter regime}

The abrupt switching of thermal regimes in the upper cave during the first cold autumn nights and the emptying of $\mathrm{CO}_{2}$ and ${ }^{222} \mathrm{Rn}$ once the winter regime is set up in a given room, led us to propose a thermoconvective interpretation of this regime, involving the intrusion of cold, dense, air in the cave. Thermal convective instabilities are controlled by the density difference between the inner gaseous mixture and the outside air. As the density of interior air is increased by around $0.43 \%$ for each $1 \%$ increase in the $\mathrm{CO}_{2}$ concentration, and by $0.35 \%$ for each temperature drop of $1{ }^{\circ} \mathrm{C}$, the $1.78 \% \mathrm{CO}_{2}$ content in SDJ is balanced by a $2{ }^{\circ} \mathrm{C}$ lower outside temperature (De Freitas et al, 1982). This temperature difference is obtained for the first and for the second onset of the winter regime, while the third and definite onset is triggered by a much lesser temperature difference. This corresponds to only a partial recovery of $\mathrm{CO}_{2}$ concentration, as evidenced in figure 4a. BMH01 estimated the rate of the input of low $\mathrm{CO}_{2}$ cold air at $100000-500000 \mathrm{~m}^{3} /$ day, an amount of the same order of magnitude as that of the total volume of SDJ. Yet, the inner air temperature decreases by only $2{ }^{\circ} \mathrm{C}$ in winter. Thus the thermoconvective interpretation only holds if a mechanism buffers the cave air temperature. We propose that the partial condensation of water present in the cave air could constitute this mechanism. Assuming a latent heat of vaporization of water of 2.5 $10^{6} \mathrm{Jkg}^{-1}$, a specific heat of the outer air of $10^{3} \mathrm{Jkg}^{-1} \mathrm{C}^{-1}$, a temperature difference of 
$7{ }^{\circ} \mathrm{C}$ between the cold outer air and the inner water saturated cave air, and a saturation vapor pressure of $1400 \mathrm{~Pa}$ for water at $12{ }^{\circ} \mathrm{C}$, we compute that $100000 \mathrm{~m}^{3}$ of cold air entering the cave is able to condense $350 \mathrm{~kg}$ of water, which is low when compared with the $3300 \mathrm{~kg}$ of water brought by $100000 \mathrm{~m}^{3}$ of wet air leaving the cave each day. This mechanism could also explain the large amount of mist observed in winter below the cave entrance. This water condenses on the floor and on the walls situated under the Aven opening. As this water is in chemical desiquilibrium with the rock (De Freitas and Schmekal, 2003), dissolution or precipitation will result on the rock walls. Thus, the areas located at the interface with the outside air during winter regime are probably not compatible with long term conservation of fragile elements such as paintings or some types of speleothems.

\subsubsection{Regime switching in the different compartments of the Aven d'Orgnac}

The switching to winter regime is delayed in the SRB, as seen in figure $4 \mathrm{~b}$. This figure also shows that the difference between the GC and the SRB air temperatures is nearly $1.3{ }^{\circ} \mathrm{C}$ at the transition, which is insufficient to balance the density step due to the abrupt increase of $1.5 \%$ of the $\mathrm{CO}_{2}$ concentration recorded by $\mathrm{BMH} 01$ at the SRB entrance just before the onset of the winter regime in this room. Nevertheless, we observe (figure $4 b$ ) that the winter regime sets on in this compartment during the night of November 22. Both the drop in the $\mathrm{CO}_{2}$ concentration at the regime switch recorded by BMH01 from SDJ to the bottom of SR by and the temperature records of figure $4 \mathrm{~b}$ show that this transition propagates stepwise toward the far rooms.

The switching toward winter regime corresponds to a temperature difference that is close to the one required for thermoconvective instantaneous destabilization of the SRB 
atmosphere. Moreover, BMH01 have shown that the transitions were triggered by low atmospheric pressure events during the winter of 1996-1997. The flow needed to restore the pressure equilibrium in the different cave rooms is likely to destabilize the $\mathrm{CO}_{2}$ front and therefore may help to initiate the growth of a thermoconvective instability at the entrance of SRB. In the Canyon, which is a depression, $5 \mathrm{~m}$ deep and 15 to $25 \mathrm{~m}$ wide, inside the SR floor, our observations lasting since 1997 suggest that the regime switch does not occur every year and that the winter regime lasts only for a few days. BMH01 have defined the confinement of a cave compartment, linking it to the stability of its environmental conditions. Confined rooms are in steady state and only receive a gaseous supply from the microfissural network that is also in steady state. On the contrary, open rooms receive outside air through the macrofissural network or through large openings. They are also called ventilated room and are generally not in steady state. Rooms that receive energy, due the lightning, or $\mathrm{CO} 2$ due to breathing of the visitors are not in a confined state if their environmental parameters are significantly changed. Thus SDJ and other rooms of the Aven d'Orgnac are not confined during the winter regime, since they are ventilated. However they may present a confined state during summer. SDJ is not confined during summer due to the electric power used to light the room during tourist visits.

We have shown that a thermoconvective mechanism is able to account for the succession of the different regimes inside the upper rooms of the Orgnac-Issignac cave system. Every summer, the different rooms of the Orgnac-Issignac cave system are in a confined state, with a steady and constant atmospheric composition in the different compartments. This steady atmosphere results from a dynamical equilibrium since the whole cave system is swept by a continuous flow of $\mathrm{CO}_{2}$ rich air which was estimated 
at $50000-100000 \mathrm{~m}^{3} /$ day at the Aven opening (BMH01). Every early winter, the outside temperature decreases gradually and tends to produce an inverse stratification at the SDJ entrance, since the inner air temperature is almost stable. The onset of the winter regime in SDJ has been demonstrated to correspond to a thermoconvective destabilization of this room atmosphere. As a consequence, the air temperature, the $\mathrm{CO}_{2}$ concentration and the ${ }^{222} \mathrm{Rn}$ activity decrease, and a boundary layer with a steep composition and temperature gradient is generated in $\mathrm{GC}$, which is the next compartment. Lower compartments open successively, and the winter regime sets on downward to SR. However, each compartment lower than SDJ opens before the inverse density stratification is build up at its entrance. Thus, the different mechanisms involved in the onset of the winter and the summer regimes are still to be assessed. As temperature and $\mathrm{CO}_{2}$ concentration gradients induce density changes of the same order of magnitude, double diffusive convection is expected with diffusion of both heat and chemical species inside boundary layers. Such convective instabilities have been mainly studied inside the ocean were both salinity and temperature gradients are present and are able to produce a staircase pattern (e.g Kelley et al., 2003) where both temperature and composition are stratified with gradient located at the horizontal boundaries of convection cells. We suggest that that additional information on the state of the atmosphere of the Orgnac cave system could arise from thermal and compositional monitoring near a room boundary, where the most significant gradients are likely to be located.

\subsection{Thermal record in the Salle Plane confined room}


This section deals with a six day vertical profiling inside the Salle Plane (SP) room, and with the air temperature records in remote rooms of the Orgnac-Issirac cave system. SP is a remote cavern, located more than $500 \mathrm{~m}$ away from the Aven entrance (figure 1a), where the winter regime has never been observed. It only subjected to a few visits by speleologists with no permanent effect. Our air temperature profile includes 6 sensors placed every $5 \mathrm{~m}$ along a vertical line inside SP. The sensitivity of our data may be estimated from the sensor inserted in the ground, which is a reference sensor, calibrated by the manufacturer with the data logger. After a temperature drop during the first day, this sensor recorded a steady temperature with a noise less than $0.005{ }^{\circ} \mathrm{C}$, which has been considered as the noise level for the whole data set. The sensors indicate that the temperature of this remote room is very stable, with a maximum amplitude of $0.12{ }^{\circ} \mathrm{C}$ over the whole vertical profile, and less than $0.03{ }^{\circ} \mathrm{C}$ of daily variation on each individual sensor (figure 6). One notes that the warmest sensors are located near midprofile. However, the most striking feature of these data is the half daily signal, which is in phase in each sensor. This led us to compare the inner air temperature with the atmospheric pressure, where a semi diurnal-signal is also present due to atmospheric tides (Lindzen, 1971). However, due to the failure of our inner pressure sensor during the thermal experiment, the outside air pressure recorded by the nearby French Meteorological Center of Lana was used. We found a noticeable cross-correlation between $\mathrm{T}$ and the pressure first time derivative, $\mathrm{dP} / \mathrm{dt}$, reaching 0.42 with dominant $12 \mathrm{~h}$ and $24 \mathrm{~h}$ periods (figure 9a), which means that the $12 \mathrm{~h}$ and $24 \mathrm{~h}$ components of both signals are correlated. However, this correlation can only provide qualitative hints since air pressure is known to vary in space at the earth surface and to be filtered inside far underground rooms. Thus, this analysis has been extended to other rooms of the 
Orgnac system using the data collected continuously during 1998 (figure 9b) and during 15 days in the winter of 1999 (figure 7), when the inner pressure sensor worked. The best correlation has been found in March, when the thermal perturbations due to the winter regime and to the summer tourist visits were minimal. This correlation was observed in SR, and decreases toward the Aven opening. For the temperatures measured in SDJ, the correlation is lower than 0.1 with no noticeable maximum near zero offset. This confirms the inference obtained from the winter regime during which no confinement was detected between CG and SDJ. The variability of the pressuretemperature relationship is explored in the next section using data from other caves monitored by our team.

\subsection{Temperature-pressure relationship in different natural cave systems}

The Gouffre d'Esparros cave, situated in the French Pyrenean foreland, includes two main superposed subhorizontal galleries (figure 8a) at 60 and $130 \mathrm{~m}$ depths, linked by a series of narrow vertical shafts. The thermal monitoring device is located in the lower gallery, which is subjected to a moderate touristic attendance (30 000 persons per year and less than 300 persons per day), except for its farmost extension, the Aragonite gallery. The only natural opening is a vertical shaft, less than $1 \mathrm{~m}$ in diameter, while an artificial entrance has been drilled, consisting of a $90 \mathrm{~m}$ tunnel, opening in the lower gallery, and sealed by two doors that are not perfectly impermeable to air. From our survey continuing since 1996, we extracted data from one year of continuous monitoring (2001) and a few days in 1999 during a tempest involving an extreme pressure drop of $30 \mathrm{hPa}$ in less than 8 hours, and for which the temperature and the

pressure have also been recorded by Perrier et al. (2001), inside an underground 
limestone quarry near Paris. No seasonal thermal regime changes have been observed in this cave and the $\mathrm{CO}_{2}$ concentration never exhibits large fast change even if a seasonality is present. This suggests that the cave is in a confined state. The air temperature of the Aragonite gallery strongly correlates with $\mathrm{dP} / \mathrm{dt}$ throughout the year 2001, with a marked peak reaching 0.60 near zero offset (figure 9c). The pressuretemperature correlation drops when approaching the artificial opening due to the tourist visits that take place throughout the year. During the storm of 1999 (figure 9c), the $12 \mathrm{~h}$ component present in the temperature and the pressure signals throughout the year disappears. However, the correlation between $\mathrm{T}$ and $\mathrm{dP} / \mathrm{dt}$ is maintained inside the Aragonite gallery, and also decreases toward the artificial opening. This suggests that the coupling of both signals is not specific to a given time periodicity.

The Chauvet cave (figure $8 \mathrm{~b}$ ) is located $7 \mathrm{~km}$ to the North East of Orgnac inside the same limestone formation and contains numerous paintings from Aurignacian age. The natural opening, initially only $30 \mathrm{~cm}$ wide, was first enlarged and then closed by a door system to restore the initial ventilation rate. The cave is only open to a very limited amount of visits of researchers. It consists of a gallery, firstly sub-horizontal, then descending slightly from the entrance of the Megaceros gallery. At this entrance, the $\mathrm{CO}_{2}$ concentration presents a sharp front with a typical jump from $1.5 \%$ to $3.5 \%$ and similar yearly variations on both sites of the front. No winter regime similar to that of Orgnac rooms has been observed in any part of the cave since the beginning of the monitoring in 1997 . The ${ }^{222} \mathrm{Rn}$ activities, similar on both sides of the front, indicate the absence of dilution effect in the atmosphere. It is therefore expected that the $\mathrm{CO}_{2}$ front originates either from the production or from the transport mechanism of $\mathrm{CO}_{2}$, i.e. either from the soil composition and activity or from the fissural network properties. Except 
during visits, the air temperatures of the different rooms are closely related to $\mathrm{dP} / \mathrm{dt}$ (figure 7), with correlations coefficients of 0.70 and 0.52 , the lowest coefficient being located near the entrance (figure 9d). Thus temperature militates for a high confinement level in this cave.

The previous examples dealt with caves presenting only one narrow upper opening, which is able to limit the cold, dense, winter air inputs, hence ensuring the confinement of the different cave rooms. Our last example is the Marsoulas prehistoric cave (figure $8 \mathrm{c})$, that consists firstly of a $40 \mathrm{~m}$ subhorizontal gallery, then dips gently to reach -6.5 $\mathrm{m}$. This cave is not open to visits except during a 3 week archeological campaign each summer. Near the entrance, the winter temperature is steady on short term period (lower than $24 \mathrm{~h}$ ), while in the summer it is highly variable. However, the temperature and composition of the atmosphere of the remote cave always remains stable. Similar observations, also inside a subhorizontal cave, have also been reported by Smithson (1991). Using the data recorded in January 2005, a period with no visits, we found a correlation 0.5 inside the far cave (figure 9e). This indicates that the far cave is confined during winter.

Consequently, comparing our records in various caves led us to propose that the relationship between $\mathrm{T}$ and $\mathrm{dP} / \mathrm{dt}$ could be used as a clue to the confined character of a given room. Perrier et al., (2001), interpreted the air temperatures recorded in an abandoned limestone quarry near Paris, using the ratio (transfer function) between the spectra of temperature and of pressure. They show that this ratio is proportional to frequency between $24 \mathrm{~h}$ and $1 \mathrm{~h}$ periods, which is strictly equivalent to the proportionality between $\mathrm{T}$ and $\mathrm{dP} / \mathrm{dt}$, since signal analysis theory states that derivating a signal is equivalent to multiplying its spectrum by frequency. We tried to compute a 
transfer function between $\mathrm{P}$ and $\mathrm{T}$ with our data, and found results analogous to those of Perrier et al. (table 1). However, we found that our transfer functions were noisy, especially near the $12 \mathrm{~h}$ and the $24 \mathrm{~h}$ periods, that represent the main components of the signals, so that a linear regression as function of frequency was unstable. In this case the transfer function at $24 \mathrm{~h}$ and $12 \mathrm{~h}$ were computed from data filtered around these frequencies. This led us to propose that the relation between $\mathrm{T}$ and $\mathrm{dP} / \mathrm{dt}$ could be easier established with their cross-correlation, although no transfer function can be computed by this method. In our examples this correlation is high in the far end of confined caves, and drops near their entrance, even when the whole cave was suspected to be confined from its compositional variations, while inside non confined caves, this correlation is very low. This implies that far rooms of a karstic system may exhibit a confined behavior even if they undergo a $\mathrm{CO}_{2}$ rich air circulation, with a quasi-steady state, where only weak temperature changes are governed by pressure. In contrast if a room receives cold outside air with fast transfer times, as SDJ does or warm air resulting from tourist visits, pressure-induced temperature changes are hidden by the heat transfer due to advection, and no simple relationship with the pressure-time derivative is observed. This relationship is best supported by a cross-correlation analysis, but may also be suspected when a $12 \mathrm{~h}$ period is present in the temperature signal or from the spectral ratio of temperature to pressure.

\section{INTERPRETATION OF THE PRESSURE-TEMPERATURE RELATIONSHIP INSIDE CONFINED CAVE ROOMS ATMOSPHERES}


Here, we explore the physical mechanisms that are likely to operate inside a cave and could comply with our observed relationship between $\mathrm{T}$ and $\mathrm{dP} / \mathrm{dt}$. Firstly this relationship points to the following equation :

$$
\mathbf{T}=\mathbf{T}_{0}+\mathbf{a} \frac{\partial \mathbf{P}}{\partial \mathbf{t}}
$$

where $T_{0}$ is a constant temperature, for example that of a rock volume considered as an infinite reservoir exchanging heat with the room atmosphere. The Fourrier transform of this equation is:

$$
\underline{T-T_{0}}=i \omega a \underline{P}
$$

where $\varpi=2 \pi f$ is the signal pulsation, $f$ its frequency, $\mathrm{i}^{2}=-1$, and the underlined variables refer to the component of this variables at the $\omega$ pulsation. Equation (1), however, does not provide any interpretation since it does not include any physical mechanism. Besides, the laws of thermodynamics state that increasing the pressure of air generates heat, while a pressure drop absorbs heat. If the gaseous volume is thermally insulated, an adiabatic transformation occurs, and the gas temperature changes according to the amount of heat generated or absorbed. This results in a temperature to pressure ratio of $80 \mathrm{~m}^{\circ} \mathrm{C} / \mathrm{hPa}$ for dry air. Perrier et al. (2001) propose that inside a vapor-saturated gas, pressure changes will induce evaporation and condensation of water that partly absorb the heat generated, resulting in a lower $\mathrm{dT} / \mathrm{dP}$ ratio of $42 \mathrm{~m}^{\circ} \mathrm{C} / \mathrm{hPa}$. However, this implies that the gas is always at $100 \%$ saturation and that condensation and evaporation are instantaneous. At the opposite of the adiabatic behavior, the case of an isothermal atmosphere should be considered. An isothermal atmosphere is characterized by infinitely fast heat exchanges with large size reservoir at constant temperature $\mathrm{T}_{0}$, which could be located inside the rock volume surrounding the cave. Both the isothermal and 
the adiabatic behaviors are theoretical extremes that correspond to idealized cave atmospheres, exchanging heat infinitely fast or infinitely slowly with the outside medium. Since the $\mathrm{dT} / \mathrm{dP}$ coefficients computed in the previous section are lower than $15 \mathrm{~m}^{\circ} \mathrm{C} / \mathrm{hPa}$ the atmosphere of our different cave rooms is isothermal rather than adiabatic. Thus, we now consider in equation (3) both pressure-induced heating and cooling (first right hand side term) and heat exchange with a reservoir proportional to the difference with its temperature $\mathrm{T}_{0}$ (second right hand side term). The constant $\mathrm{B}$ allow to tune this equation from purely adiabatic behavior $(B=0)$ to an isothermal one $(\mathrm{B}=\infty)$.

$\frac{\partial T}{\partial t}=A \frac{\partial P}{\partial t}-B\left(T-T_{0}\right)$

Taking the Fourier transform of this equation yields :

$\underline{T-T_{0}}=\frac{i \omega A \underline{P}}{i \omega+B}$

This implies that under a frequency defined by: $B>>i \varpi$

$\underline{T-T_{0}}=i \omega \frac{A}{B} \underline{P}$

which is equivalent to (2) with $\mathrm{a}=\mathrm{A} / \mathrm{B}$. This implies that at low frequency equation (3) is equivalent to (1) that describe our observations. (3) also implies that at a high frequency, defined by $\mathrm{B}<<\mathrm{i}$, temperature is no more controlled by $\mathrm{dP} / \mathrm{dt}$ but by $\mathrm{P}$. This could correspond to the correlation between $\mathrm{T}$ and $\mathrm{P}$ present in our records at high frequencies. However, at the 15 mins time step used in our surveys (5 mins at Marsoulas), this correlation is low and the correlation with $\mathrm{dP} / \mathrm{dt}$ dominates the whole signal. The time constant at which the thermal exchange occurs with the infinite 
reservoir is given by the period at which a significant correlation between $\mathrm{T}$ and $\mathrm{P}$ is observed, which is lower than one hour in our surveys. We conclude that equation (3) is able to account for our data inside confined rooms. It must be emphasized, however, that (3) relies on only one temperature for the cave room atmosphere, while thermal gradients are observed during our experiment in Salle Plane. Thus (3) only provides an approximation of the thermal exchanges around a cave room.

We now focus on the physical thermal exchange mechanisms included in equation (3). Perrier et al. (2001) first proposed that their temperature measurements inside an abandoned limestone quarry could be induced by pressure changes and introduced two types of relaxation mechanisms. The first one involves a high Rayleigh number convection triggered by the geothermal gradient, allowing conductive heat transfer across a millimetric thin boundary layer, while the second one relies the evaporation and condensation of water on rock walls. His equations reduces at low frequency, between the $24 \mathrm{~h}$ and $4 \mathrm{~h}$ periods, to a formula equivalent to equation (1). So the mechanisms proposed by Perrier et al. (2001) are able to explain our data. The advantage of their model is that it relies on precise physical mechanisms. One of these mechanisms is the high Rayleigh number thermal convection which implies that the temperature gradients are localized inside thin boundary layers near the cave walls. Due to the $5 \mathrm{~m}$ vertical resolution of our thermal profile at Salle Plane is not able to detect these boundary layers. However, our data does not favor high Rayleigh number thermal convection since the highest temperatures are located near mid-profile. In addition, Perrier et al. model require the adjustment of three free parameters to fit the temperature data, just as equation (3) does. So even if heating or cooling during pressure changes can be considered as a fundamental mechanism controlling confined cave atmospheric 
temperatures, there is no indication that all significant effects are taken into account by Perrier et al. model.

BMH01 have shown that the rooms of the Orgnac-Issirac cave system are far from being closed volumes, since they are exchanging gas with other rooms and with the porosity of the karstified rock volume. Thus pressure changes are likely to induce temperature changes due to advection of different temperature gases inside the room. A pressure change of $20 \mathrm{hPa}$, i.e. $2 \%$, will result in a $2 \%$ change of the amount of gas inside a given room at constant temperature. If the pressure change occur adiabatically, this amount should be divided by $\gamma$, which is the ratio of the specific heat at constant pressure by the one at constant volume, which is near 1.4 for air. As temperature changes are much lower than adiabatic, a value of $2 \%$ is considered. This will induce a $2 \% \times \Delta \mathrm{T}$ temperature change inside the room if $\Delta \mathrm{T}$ is the temperature difference between the incoming gas and that of the cave air. This will produce a temperature to pressure ratio near $1 \mathrm{~m}^{\circ} \mathrm{C}^{*} \Delta \mathrm{T} / \mathrm{hPa}$, that should be compared to the purely adiabatic coefficient of $80 \mathrm{~m}^{\circ} \mathrm{C} / \mathrm{hPa}$ for dry air, to the coefficient of $42 \mathrm{~m}^{\circ} \mathrm{C} / \mathrm{hPa}$ computed by Perrier et al. (2001) for water saturated air, and to the coefficient observed in our different cave spanning from 0.4 to $20 \mathrm{~m}^{\circ} \mathrm{C} / \mathrm{hPa}$. Hence this effect could be significant if several ${ }^{\circ} \mathrm{C}$ temperature differences are present between the gaseous masses surrounding a confined room.

Finally, as $\mathrm{CO}_{2}$ rich air is continuously injected from the fissural network into the different rooms of a karstic system, every event able to alter the injection rate may be considered. Pluviometry and the internal fluid pressure are suspected to be correlated with the outside air pressure and are able to generate variability in this injection rate and thus temperature change in the cave if thermal gradients are present inside the cave 
walls. This suggests that modeling of microfissural two phase flow could help to better understand the internal cave climate.

\section{DISCUSSION AND CONCLUSION}

The air temperature records presented here aim to complete those of Bourges et al. (2001), where $\mathrm{CO}_{2}$ concentration measurements helped to assess the exchanges between a limestone cave of a karstic system and the outside environment. Thermal and $\mathrm{CO}_{2}$ monitoring continuing over more than 5 years, plus ${ }^{222} \mathrm{Rn}$ data during dedicated periods show that these three variables present a marked seasonality in the Orgnac cave first rooms. During the summer regime, the cave air temperature is stable and does not correlate with the temperature outside. In contrast, during the winter regime, the cave temperature is characterized by large oscillations, more pronounced near the entrance and correlated with the outside temperature. We show that the air temperature pattern during this winter regime can be explained by thermal convective flow of the cold, dense outside air in the cave, and that the onset of this regime is triggered during the first cold nights whereby an inverse density stratification sets on at the cave opening. This winter regime propagates in a few weeks toward the Salles Rouges Balcony, with decreasing amplitude. The onset of the winter regime inside one compartment of the cave is simultaneous with the fall of its $\mathrm{CO}_{2}$ content. Our measurements show that active thermoconvective circulation inside the Salle de Joly might be responsible for the $\mathrm{CO}_{2}$ emptying events, whereas it cannot be involved alone in Salles Rouges and Salles Rouges Balcony, since the observed temperature gradient is insufficient to induce 
inverse stratification between the cold $\mathrm{CO}_{2}$ free outside air and the $\mathrm{CO}_{2}$ rich air of the cave. Thus, other mechanisms, involving pressure, temperature and $\mathrm{CO}_{2}$ production are still to be explored in order to explain the $\mathrm{CO}_{2}$ dynamics inside the far cave system. Taking into account several other examples at our disposal and those already published by other researchers, the Orgnac type winter regime seems to characterize caves with a large upper opening such as an Aven. Thermal convection is also active in caves presenting several large openings at different heights of a mountain flank (Andrieux, 1970 ; De Freitas et al., 1982), with a completely different ventilation pattern. Some caves presenting an upper opening but without an active microfissural system, are also open to cold outside air during winter, but are not subjected by an outflow of $\mathrm{CO}_{2}$ rich air able to drain them during the summer. Thus cold air and even snow accumulate at the base of these caves, known as "cold caves" by speleologists. Even for caves with no upper opening, thermocompositional convection might be triggered through vertical circulation inside the macrofissural network, if this network is not clogged by sediments.

In the Salle Plane, a room situated more than $500 \mathrm{~m}$ away from the entrance, the air temperature is never controlled by the outside temperature but rather by the derivative of pressure, $\mathrm{dP} / \mathrm{dt}$. A similar correlation between $\mathrm{dP} / \mathrm{dt}$ and $\mathrm{T}$ has been found in the deepest part of the 3 other cave examples presented in this paper, which do not have a large upper opening. This may be explained by pressure-induced heating and cooling of the cave atmosphere. These temperature changes are limited by heat exchanges between the inner atmosphere and a large constant temperature rock volume surrounding the cave. The definition of the time constant of this exchange is limited by the poor resolution of our data at high frequency, but it can be estimated to be lower than one 
hour. This interpretation is an extension of that proposed by Perrier et al. $(2001,2004)$ for underground quarries, and our data could also be fitted with the model of Perrier et al., owing to its three free parameters.

We found that inside our confined cave examples, the cross-correlation between temperature and the derivative of pressure was high with a maximum located near the zero offset and exceeding 0.5 , and that this coefficient was deteriorating toward the openings of the caves, even when the stability of the temperature and/or of the chemical composition indicated a noticeable confinement state inside the whole cave. We propose therefore that this cross-correlation could be used to estimate the degree of confinement of a given room.

Our observables define two different processes inside the Orgnac Issignac karstic system. Inside the open volume the winter regime consists in thermoconvective ventilation and results in seasonal $\mathrm{CO}_{2}$ emptying events. Inside a confined volume, hygrometry and $\mathrm{pCO}_{2}$ are stable and slight temperature variations are produced by the pressures changes. Since $\mathrm{CO}_{2}$ is involved in the precipitation of carbonate that constitutes the speleothems used for paleoclimate reconstructions, researchers should be aware that laminated concretions belonging to a permanently confined volume or to an open cave could provide different climatic proxies.

Yet, it should be noted that a major characteristic of the caves of a karstic system is that they are continuously exchanging air, $\mathrm{CO}_{2}$ and water with the outside medium through different size openings (underground rooms, micro-and macrofissures). Thus a volume much larger than the simple underground rooms is involved in the control of internal cave atmospheres. The thermal and compositional stability of these atmospheres do not denote a closed system but results from steady state exchanges with the outside medium 
that depend largely on the size of the various openings, the clogging of these openings by karstic sediments, and on the conditions imposed at the boundary with the outside air. The fluxes involved in the exchanges should be carefully preserved in order to ensure the constant climate required for the conservation of cave paintings and concretions. Monitoring of air temperature and composition is recommended in order to control brutal changes or drift in cave climates.

\section{AKNOWLEDGMENTS}

This work would have not been possible without the continuous support of the Environmental and Cultural French Ministries represented by DIREN Rhône-Alpes, DIREN Midi-Pyrénées, DRAC Rhône-Alpes, DRAC Midi-Pyrénées. We wish to extend our special thanks Stéphane Tocino for his help in the thermal profiling experiments and to the anonymous reviewer for helpful suggestions.

\section{REFERENCES}

Andrieux C. 1970. Contribution à l'étude du climat des cavités naturelles des massifs karstiques II: aérodynamique souterraine. Ann. Spéléol. 25: 51- 89.

Blanc JJ. 1997. Géodynamique de 1'histoire du karst: application au Sud-Est de la France. Quaternaire. 8: 91-105.

Bourges F, Mangin A, D'Hulst D. 2001. Le gaz carbonique dans la dynamique de l'atmosphère des cavités karstiques, l'exemple de l'Aven d'Orgnac (Ardèche), $C . R$. Acad. Sci. Paris. 333: 685-692. 
Box GEP, Jenkins GM, Reinsel GC. 1994. Time series analysis : forecasting and control, Prentice Hall, Englewood Cliffs, NJ, USA.

Cigna AA. 1967. An analytic study of air circulation in caves. Int. J. of Speleol. 3: 5154.

Cigna AA. 1993. Environmental management of tourist caves : the example of grotta di Castellana and grotta Grande del Vento, Italy. Environmental Geology. 21: 173-180.

Conn HW. 1966. Barometric wind in the Wind and Jewel Caves (South Dakota), Bull. Nat. Speleo. USA. 28: 55-59.

Ciry R. 1967. Les grottes: un milieu en équilibre tamponné. Spelunca. 4: 23-38.

Eraso, A. 1971. La corrosion climatica in las cavernas. Cuadernos de Espeleologicas (Santander). 5: 168-188.

De Freitas CR, Litteljohn RN, Clarkson TS, Kristament IS. 1982. Cave climate: assessment of airflow and ventilation. Int. J. Climatol. 2: 383-397.

De Freitas CR, Littlejohn RN. 1987. Cave climate : assessment of heat and moisture exchange. Int. J. Climatol. 7: 553-569.

De Freitas CR, Schmekal A. 2003. Condensation as a microclimate process: measurement, numerical simulation and prediction in the Glowworm Cave, New Zealand. Int. J. Climatol. 23: 557-575.

Fernandez PL, Gutierrez I, Quindos LS, Soto J, Villar E. 1986. Natural ventilation of the paintings room in the Altamira cave. Nature. 321: 586-588.

Geiger R. 1959. The climate near the ground. Harward Univ. Press., Cambridge, 494pp. 
Genty D. 1993. Mise en évidence d'alternances saisonnières dans la structure interne des stalagmites, Intérêt pour la reconstitution des paléoenvironnements continentaux. $C$. R. Acad. Sci. Paris. 317: 1229-1236.

Genty D, Baker A, Voka BL. 2001. Intra- and inter-annual growth rate of modern stalagmites. Chem. Geology. 176: 191-212.

Hoyos M, Solers V, Canaveran JC, Sanchez-Moral S, Sanz-Rubio S. 1997. Microclimatic characterization of a karstic cave (Candamo Cave, Northern Spain). Environmental Geology. 33: 231-241.

Kelley DE, Fernando HJ, Gargett AE, Tanny J, Özsoy E. 2003. The diffusive regime of double-diffusive convection. Progress in Oceanography. 56: 461-481.

Lindzen RS. 1971. Tides and internal gravity waves in the atmosphere. In : course of the international school of atmospheric physics. Development of atmospheric sciences. Elsevier, 137-167.

Mangin, A. 1976. Contribution à l'étude hydrodynamique des aquifères karstiques, Thesis Univ. Dijon, 124pp.

Mangin, A. 1984. Pour une meilleure connaissance des systèmes hydrologiques à partir d'analyses corrélatoires et spectrales. J. of Hydrol. 67: 27-43.

Mangin, A. 1995. Karst hydrogeology, In : Groundwater Ecology, J. Gilbert, DL. Danielopol, J. Stanford and J.H. Thorp, Editors. Academic Press. New York.

Mangin A, D’Hulst D. 1996. Fréquentation des grottes touristiques et conservation. Méthode d'approche pour en étudier les effets et proposer une réglementation, International Symposium on Show Caves and Environmental Monitoring, Cueno, Italy, 137-167. 
Mangin A, Bourges F, D’Hulst D. 1999. Painted caves conservation: a stability problem in a natural system (the example of the prehistoric cave of Gargas, French Pyrenees). $C$ R Acad. Sci. Paris. 328: 295-301.

Perrier F, Morat P, Le Mouel JL. 2001. Pressure induced temperature variations in an underground quarry. Earth Planet. Sci. Lett. 191: 145-156.

Perrier F, Richon P, Crouzeix C, Morat P, Le Mouel JL. 2004. Radon-222 signatures of natural ventilation regimes in an underground quarry. J Environ. Radioact. 71: 17-32.

Pulido-Bosh A, Martin-Rosales W, Lopez-Chicano M, Rodriguez-Navarro CM, Vallejos A. 1997. Human impact in a tourist cave. Environmental Geology. 31: 142149.

Renault, P. 1961. Première étude climatologique de la grotte de Moulis (Ariège). Ann. Spéléol. 16: 39-45.

Saar R. 1954. Etudes météorologiques dans la grotte glacée du Dachstein (Autriche). Die Hohle, 5: 49-62.

Schoeller H. 1967. Conduite de l'étude hydrogéologique et climatologique des grottes descendantes. Spelunca Mem. 4: 76-93.

Sondag F, Van Ruymbekeb M, Soubies F, Santo R, Somerhausen A, Seidel A, Boggiani P. 2003. Monitoring present day climatic conditions in tropical caves using an Environmental Data Acquisition System (EDAS). J. of Hydrol. 273: 103-118.

Soubies F, Seidel A, Mangin A, Genty D, Ronchaille J, Plagnes V, Hirookag S., Santo RA. 2005. Fifty-year climatic signal in three Holocene stalagmite records from Mato Grosso, Brazil. Quaternary International. 135: 115-129. 
Smithson PA. 1991. Inter-relationships between cave and outside air temperatures. Theor. Appl. Climatol. 44: 65-73.

Trombe, F. 1952. Traité de spéléologie. Payot, Paris. 


\section{Figure CAPTIONS}

Fig. 1. a) Map of the Orgnac-Issignac cave system, b) enlarged cross-section of the grayed area near Salle de Joly and c) cross section of Salle Plane.

Fig. 2. Temperature record in the different Orgnac cave rooms with 5 days equally weighted moving average smoothing. All curves are characterized by a 1 year periodicity, a total amplitude increasing when approaching the Aven opening and a steep drop triggered by cold outside temperatures.

Fig. 3. Spectral density of air temperature (March-July, 2002). Note that a $24 \mathrm{~h}$ component is present every room and that the $12 \mathrm{~h}$ component is null in SDJ and increases toward the deeper cave rooms.

Fig. 4 a) Switching toward the winter regime in SDJ, as recorded by the temperature, $\mathrm{CO}_{2}$ concentration, ${ }^{222} \mathrm{Rn}$ activity and relative humidity. The first switch of October 16 is marked by a drop in temperature, ${ }^{222} \mathrm{Rn}$ activity, $\mathrm{CO}_{2}$ concentration, and relative humidity, followed by a total recovery of these variables. The second switch, during the night of October 25 is only followed by a partial recovery. The definite switch to the winter regime occurs during the night of November 6 and propagates to GC on November 9. b) Propagation of the winter regime toward the remote cave rooms in 1998. (unfortunately, the outside temperature is not available for the same period). SDJ 
switches to winter regime on October $25, \mathrm{GC}$ on November 14, SRB on November 22, and SR switch occurs after December 9.

Fig. 5. Profiling experiments in SDJ. The location of measurements is indicated in figure 1. Top: summer experiment; left: temperature changes at each sensor. The curves are labeled by the height of the corresponding sensor so that the legend T8 air corresponds to the temperature recorded at $8 \mathrm{~m}$. Temperatures increase during the tourist visit, between $8 \mathrm{~h}$ and $17 \mathrm{~h} \mathrm{UT}$, but the shape of the vertical temperature profile is conserved. Due to a defect of the data logger, a perturbation occurred at the data offloads at $7 \mathrm{~h}$ UT and $21 \mathrm{~h}$ UT. Top, right mean temperature profile over the whole period.

Bottom: same as top for the winter experiment. Two different vertical profiles are observed: during the night, temperatures decrease, especially at the base of the cave where air temperature is below that of the the ground. In contrast, during the day, the temperature is almost constant for the firsts $20 \mathrm{~m}$, and increases only near the ceiling. This suggests that cold dense air flows downwards near the cave floor during the night.

Fig. 6. Temperature data in the Salle Plane during the 6 days survey of June, 2002. The ground temperature was inside the influence zone of the electric power station, especially at the beginning of the experiment so that it recorded anomalously high temperatures. The ceiling rock sensor recorded only the first few minutes of the experiment. The maximum temperatures occur near mid-profile with a major $12 \mathrm{~h}$ component in phase on all air temperature records. 
Fig. 7. Comparison of the air temperature with the first derivative of pressure in Orgnac and Chauvet during two weeks of winter 1999. CG does not correlate with $\mathrm{dP} / \mathrm{dt}$, while SR does. In the Chauvet cave, both the entrance temperature and the Megaceros room temperature correlate with $\mathrm{dP} / \mathrm{dt}$. Note that, due the low $(1 / 10 \mathrm{hPa})$ resolution of the pressure sensor, $\mathrm{dP} / \mathrm{dt}$ is noisy so that the correlation with temperature is best seen after smoothing, here with a $1 \mathrm{~h}$ equally weighted moving average.

Fig.8. Cross-section of the different caves used for comparison with Orgnac-Issignac.

Fig.9. Cross-correlation between temperature and the pressure first time derivative in various French caves. Due to the failure of our inner pressure sensor, the correlation for Salle Plane (a) uses the pressure recorded by the National Meteorological Office at the nearby Lana airport. (b) shows that the correlation decreases toward the Aven opening inside the firsts Orgnac rooms. c), d), and e) show that the correlation is stable and high in our confined cave examples. Data collected during touristic visit period have not been taken into account, since they introduce temperature perturbations that destroy the correlation with $\mathrm{dP} / \mathrm{dt}$.

\section{TABLE CAPTION}

Table 1. Temperature to pressure ratio $(\mathrm{dT} / \mathrm{dP})$ in the different caves at the $12 \mathrm{~h}$ and $24 \mathrm{~h}$ periods. These ratios are easily determined when the correlation between $\mathrm{T}$ and 
$\mathrm{dP} / \mathrm{dt}$ is high, but include probably large errors when the correlation is low, as in the SP case. Results obtained by Perrier et al. (2001) inside an abandoned underground quarry are recalled for comparison. 


\begin{tabular}{|l|c|c|}
\hline Temperature record & $\begin{array}{c}\mathrm{dT} / \mathrm{dP} \\
12 \mathrm{~h} \\
\left(\mathrm{~m}^{\circ} \mathrm{C} / \mathrm{hPa}\right)\end{array}$ & $\begin{array}{c}\mathrm{dT} / \mathrm{dP} \\
24 \mathrm{~h} \\
\left(\mathrm{~m}^{\circ} \mathrm{C} / \mathrm{hPa}\right)\end{array}$ \\
\hline Esparros : year 2001 & 4 & $12-20$ \\
\hline Esparros : tempest, 1999 & 6.4 & 10 \\
\hline Orgnac SR: March1998 & 8 & 19 \\
\hline Orgnac SP : June 2002 & 4 & 18 \\
\hline Marsoulas: January 2005 & 0.4 & 0.64 \\
\hline Chauvet: January 1999 & 3 & 6 \\
\hline Perrier et al. (2001) & 4 & 8 \\
\hline
\end{tabular}

TABLe 1 


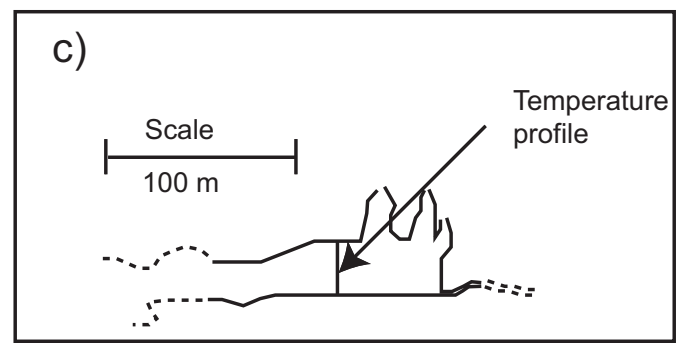

a)

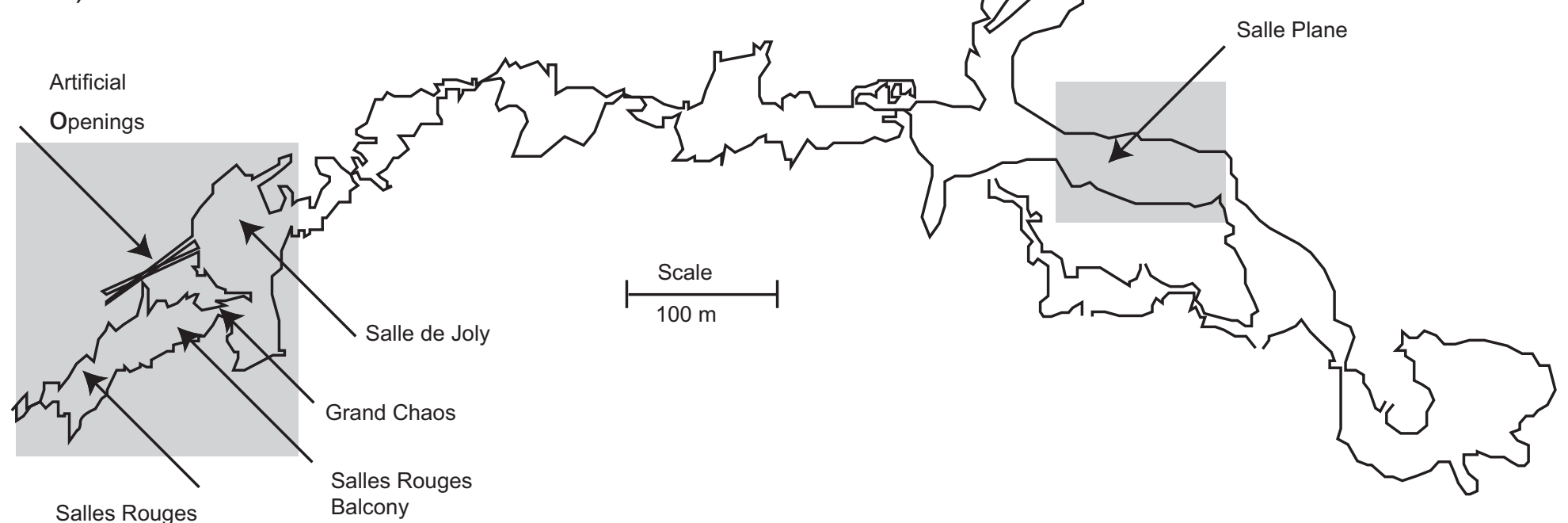

b)

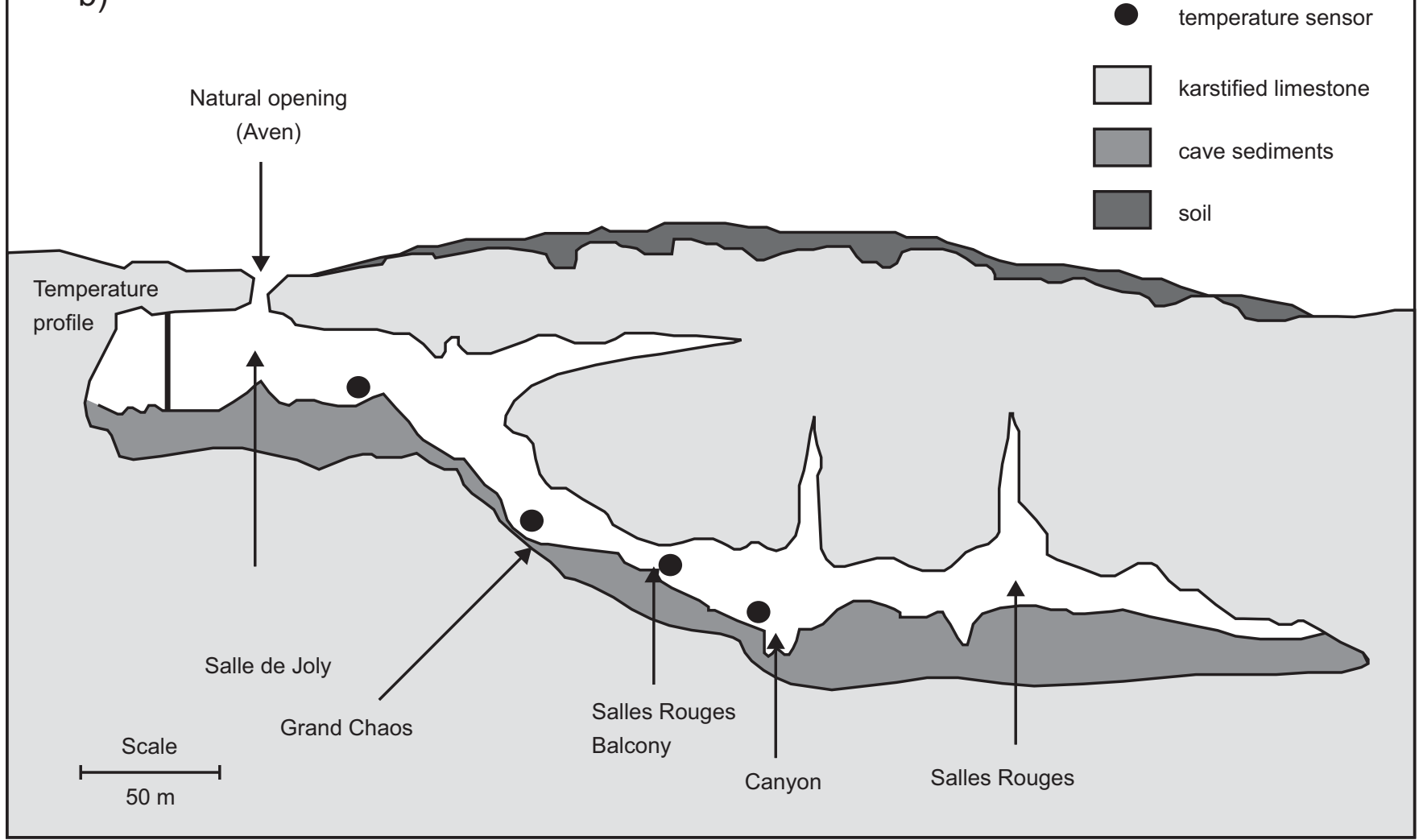

Figure 1 (Bourges et al.) 

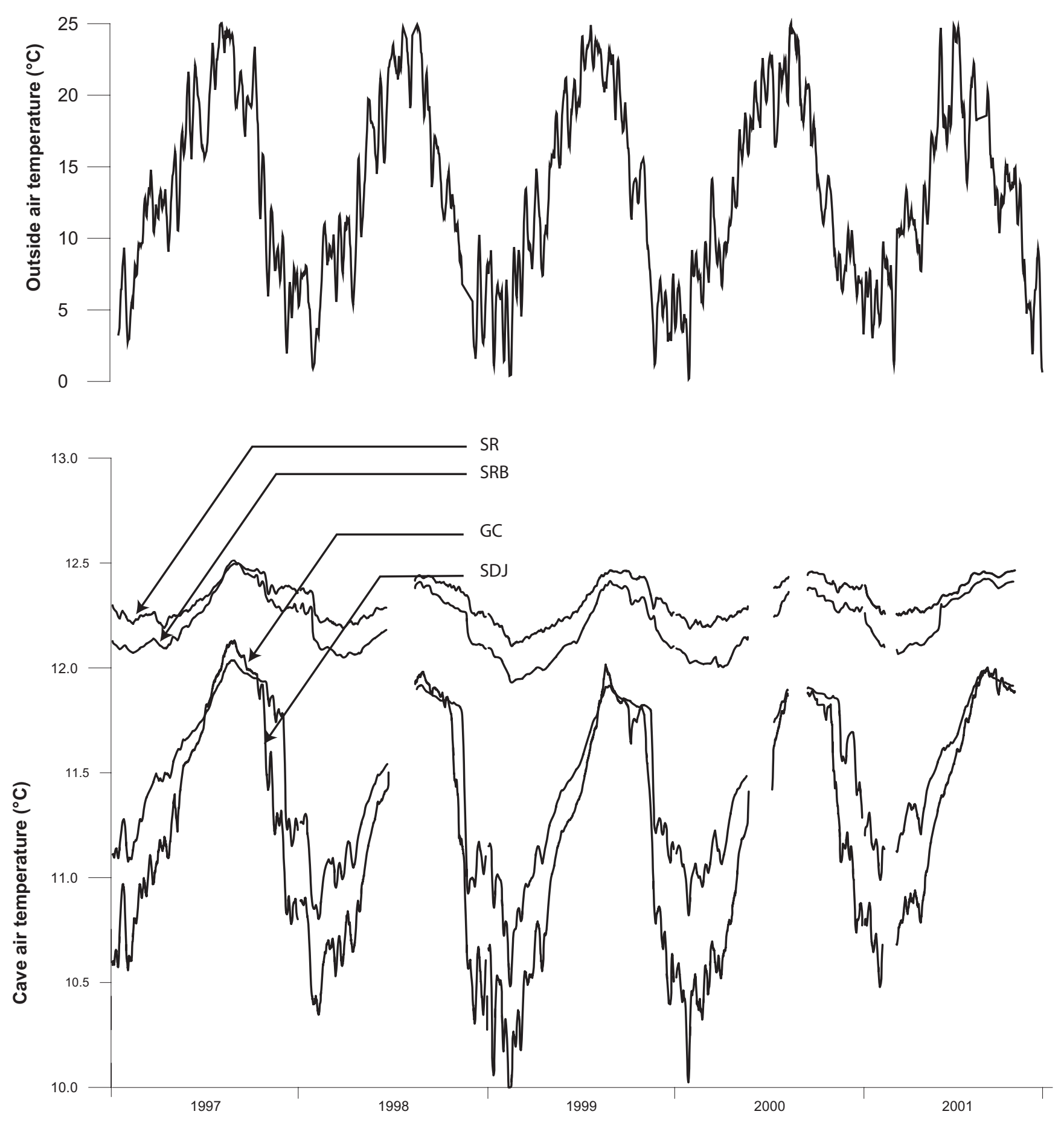

Figure 2 (Bourges et al.) 

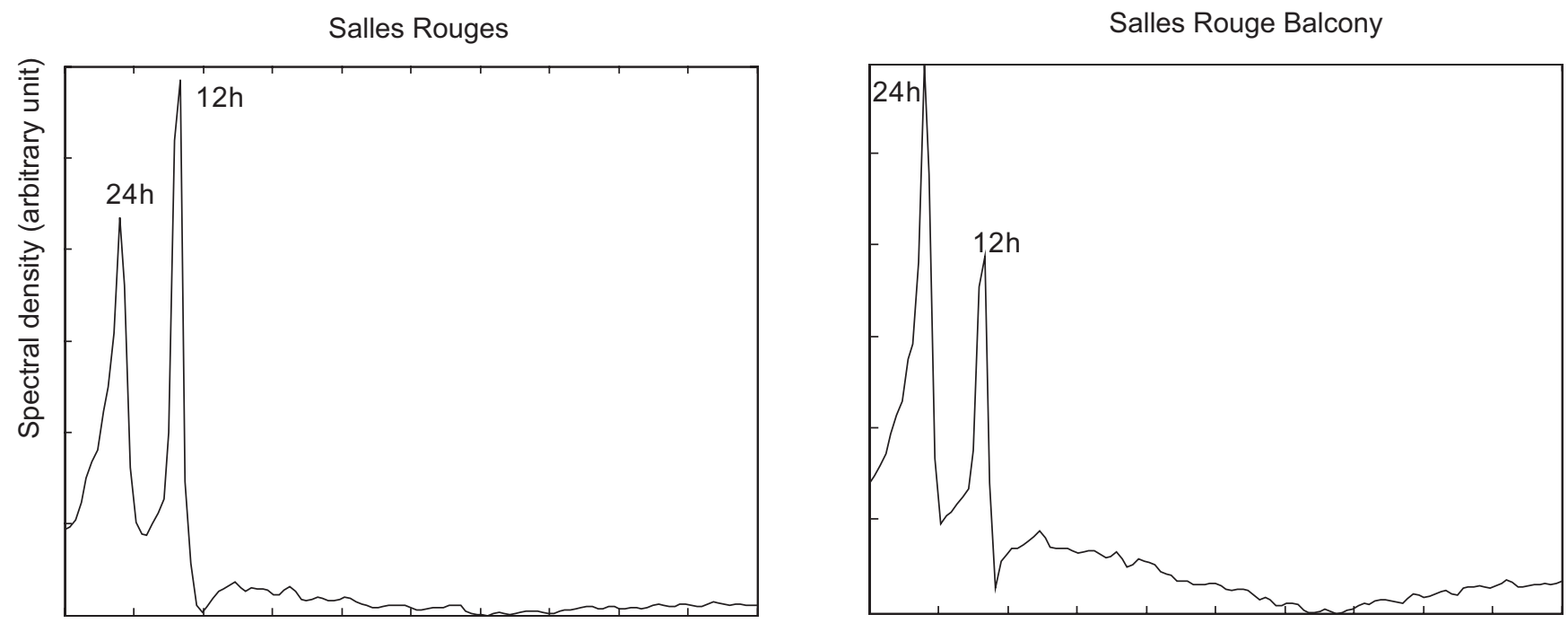

Grand Chaos

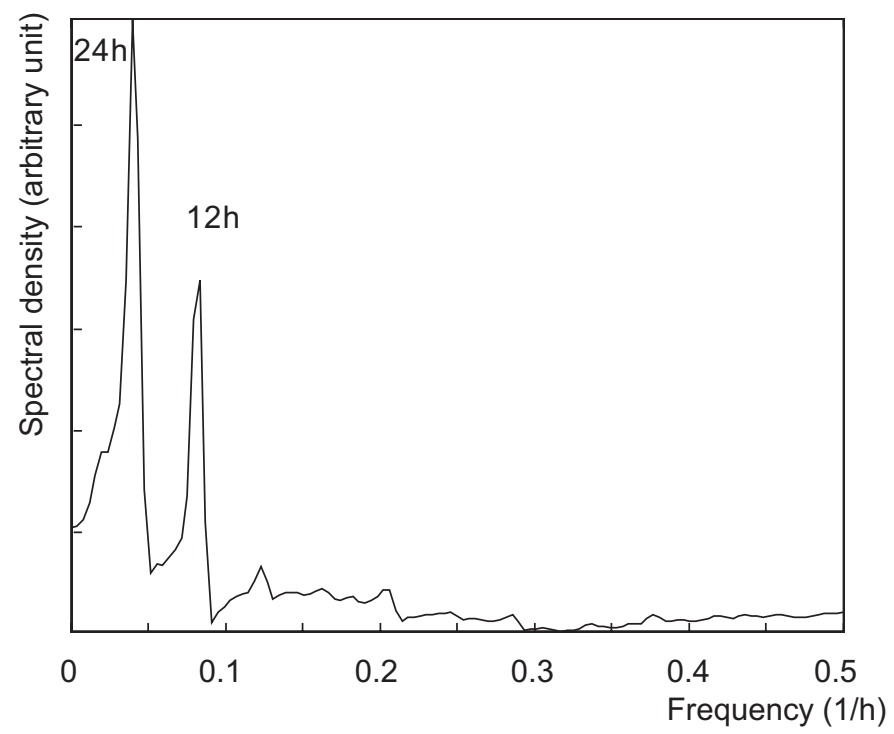

Salle de Joly

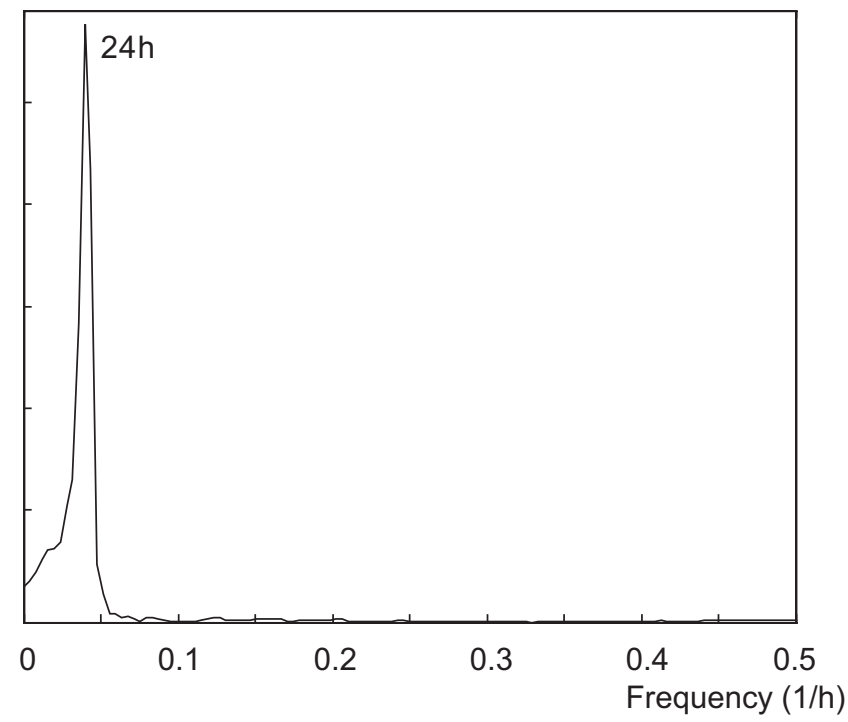

Figure 3 (Bourges et al.) 
a)
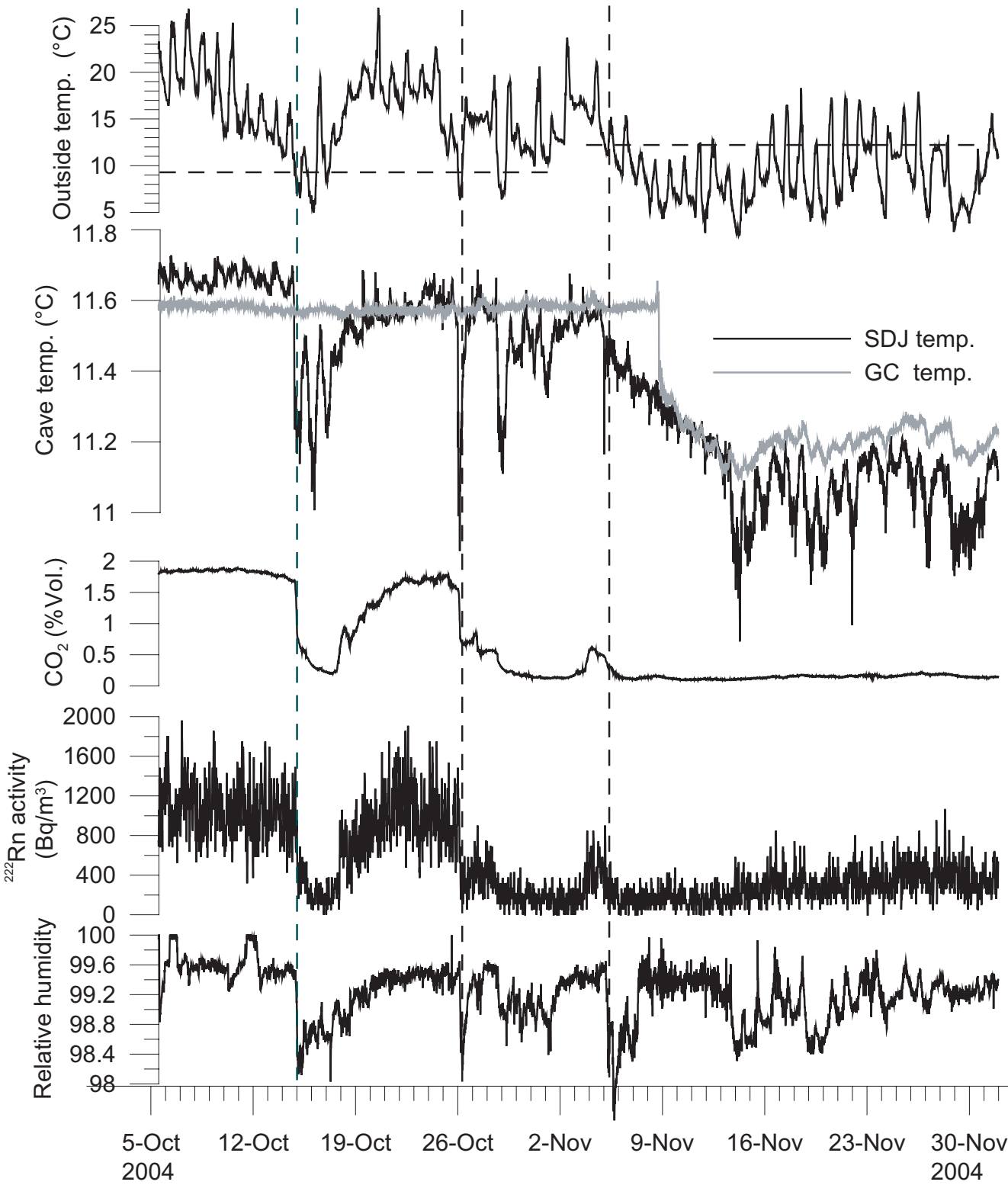

b)
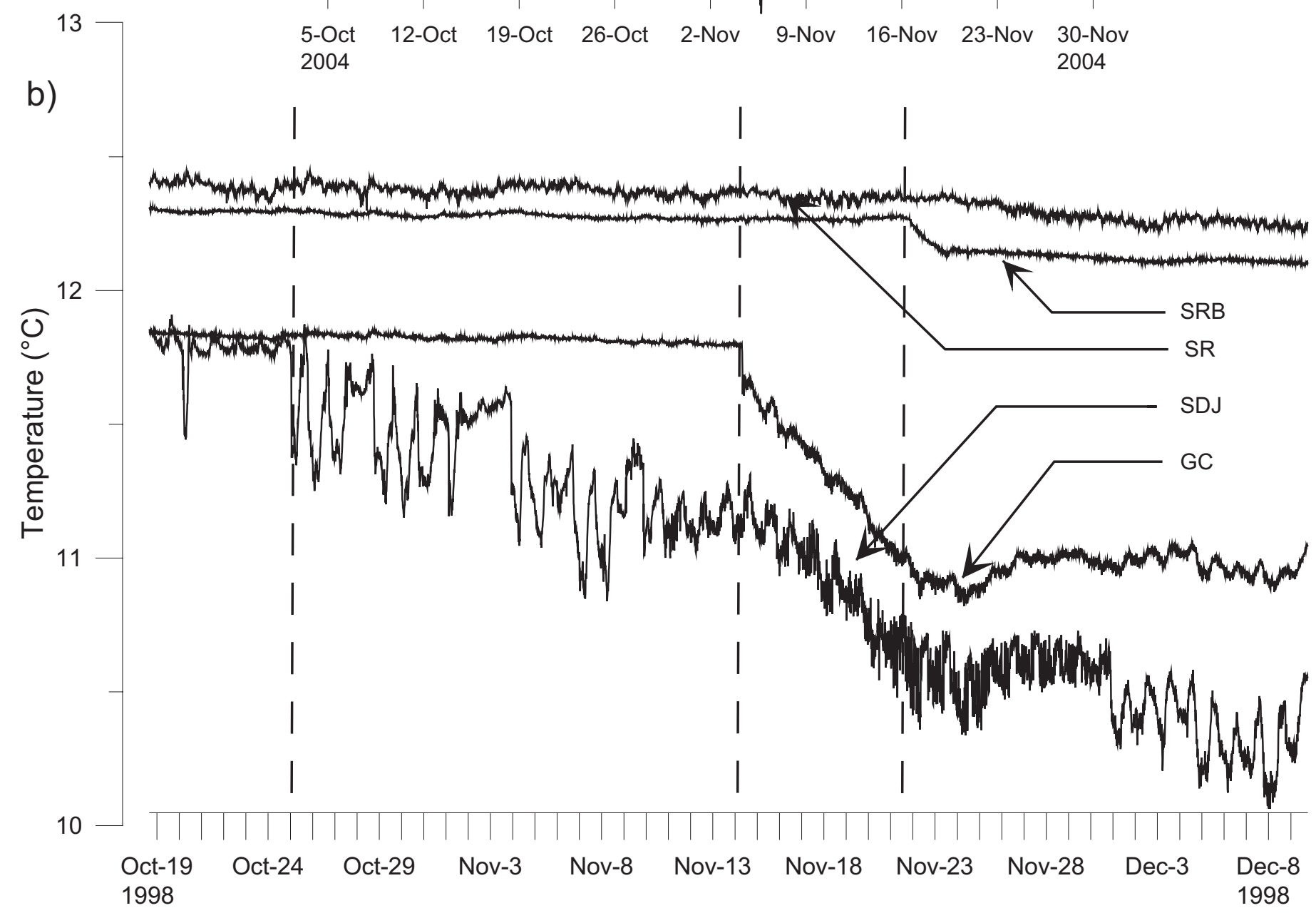

Figure 4 (Bourges et al.) 

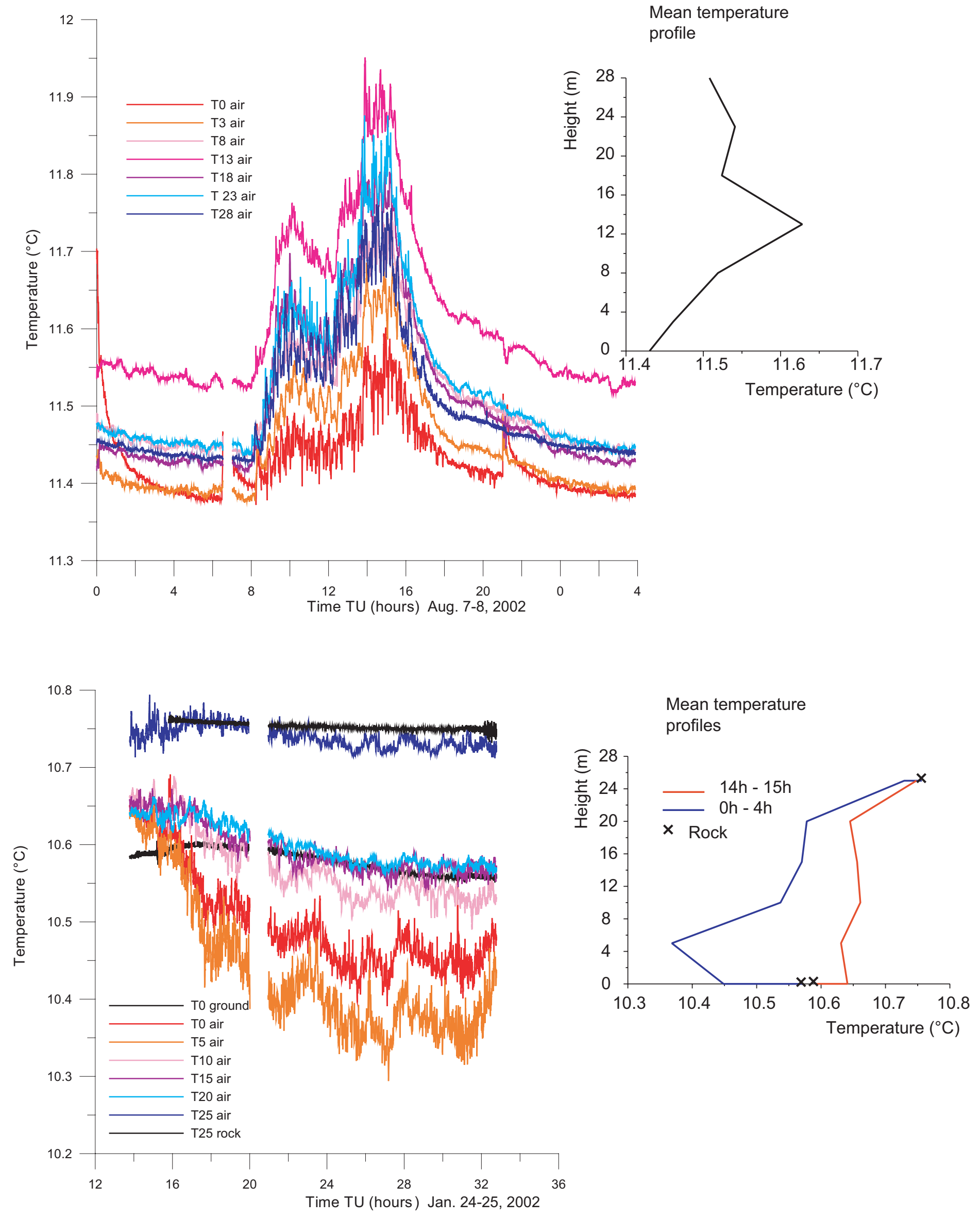

Figure 5 (Bourges et al.) 


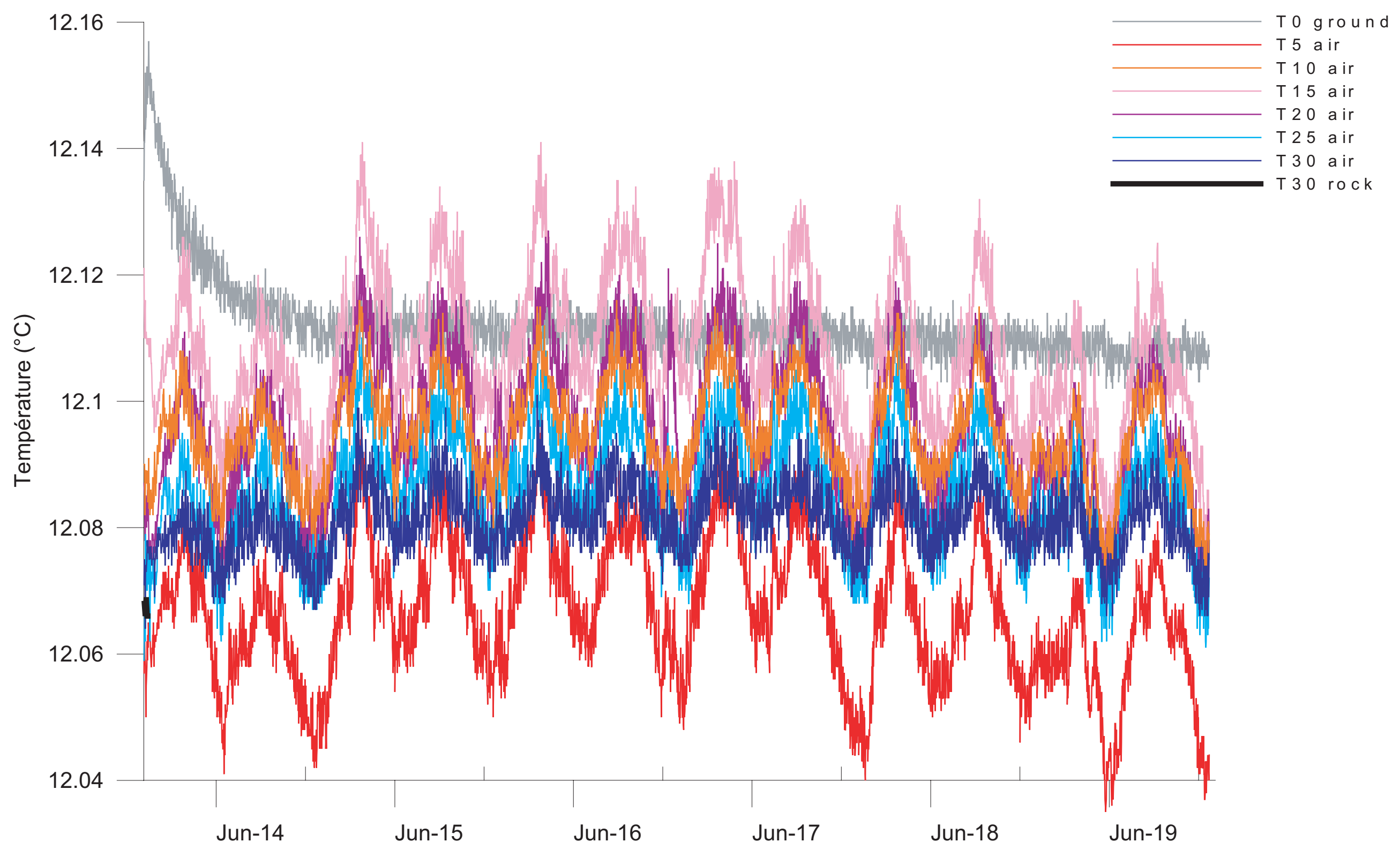

Figure 6 (Bourges et al.) 


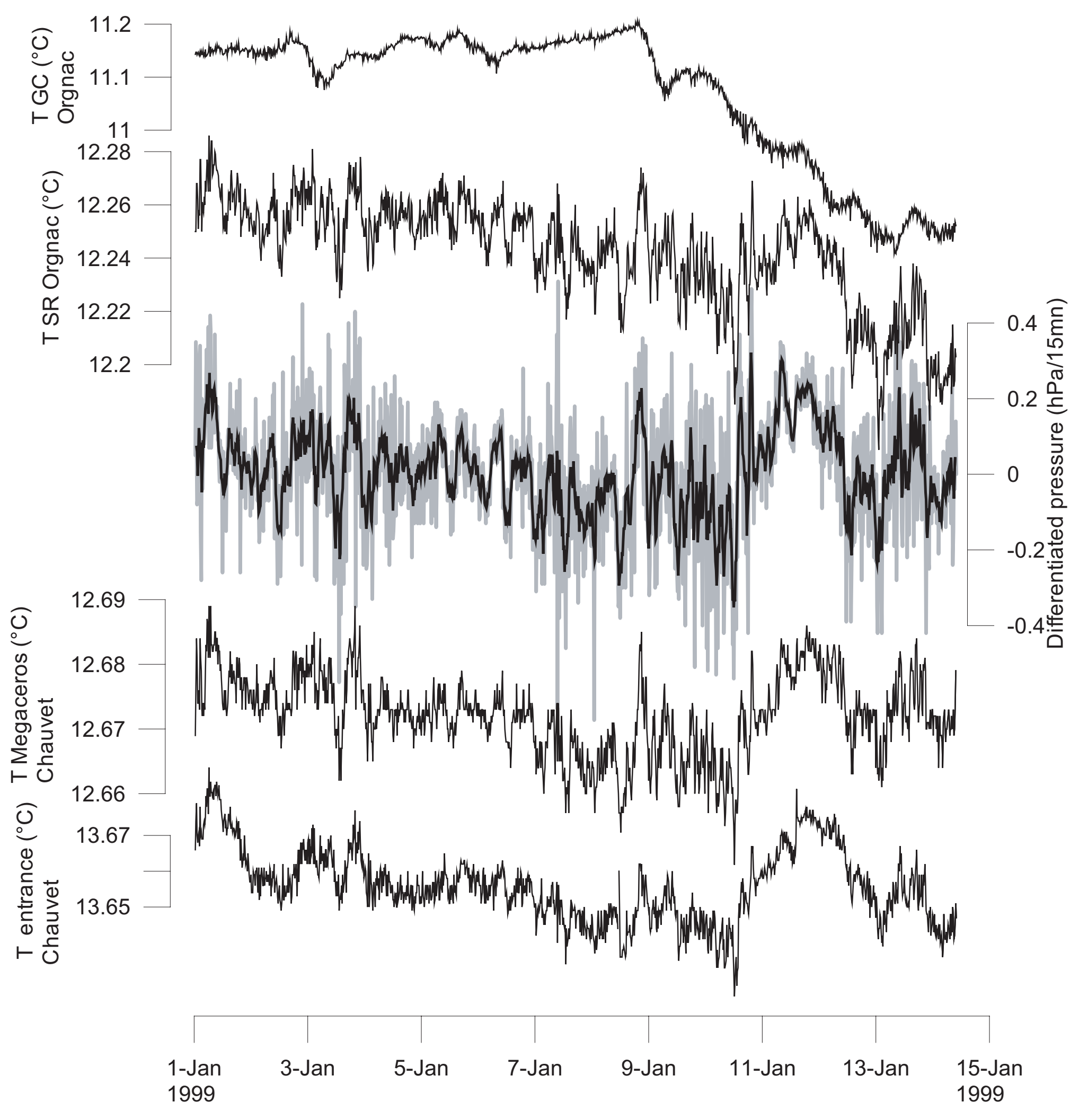

Figure 7 (Bourges et al.) 


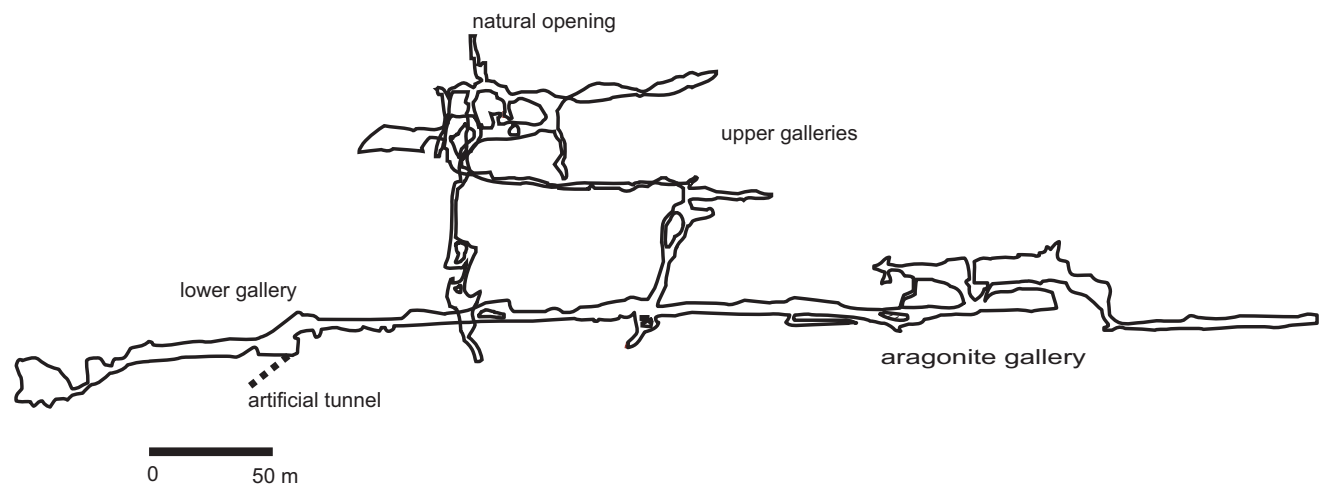

a) Esparros cave

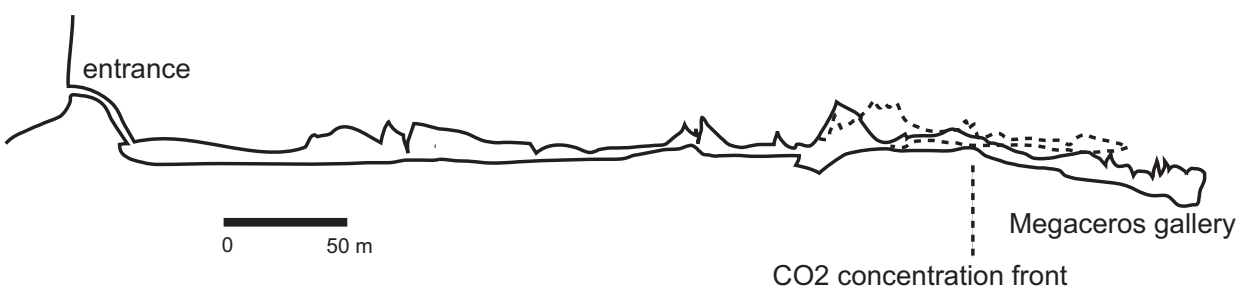

b) Chauvet cave

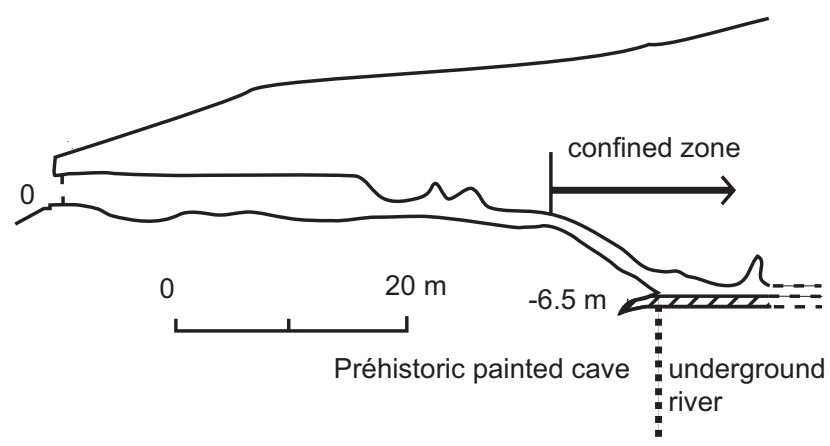

c) Marsoulas cave

Figure 8 (Bourges et al.) 
a) Orgnac Salle Plane

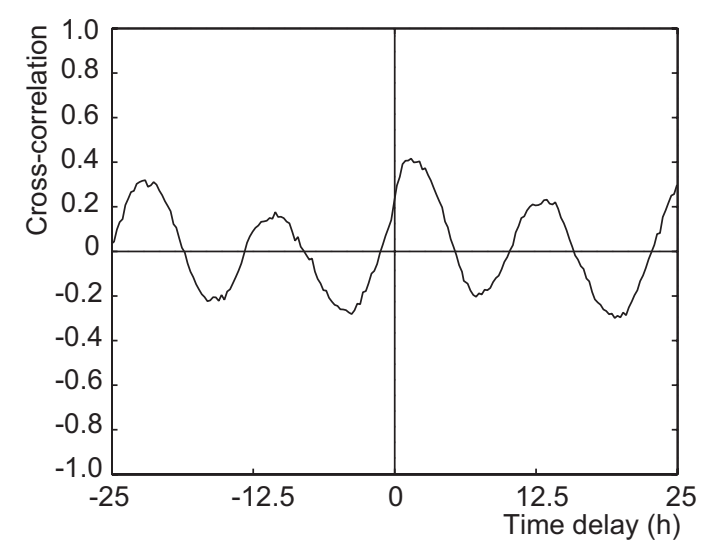

c) Esparros

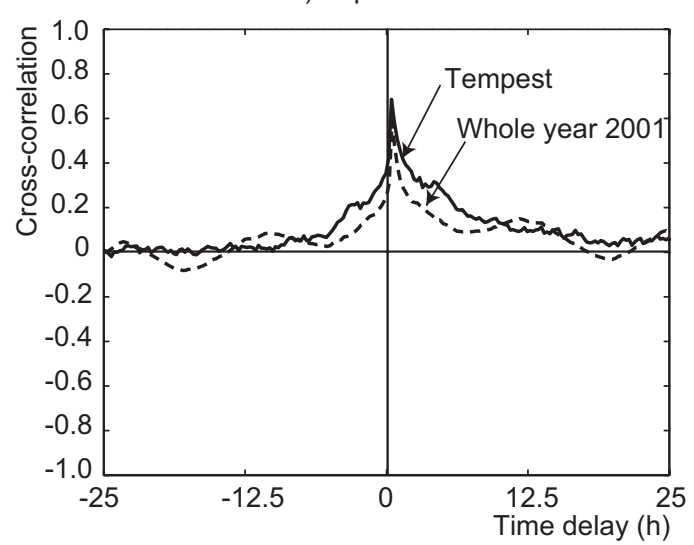

e) Marsoulas

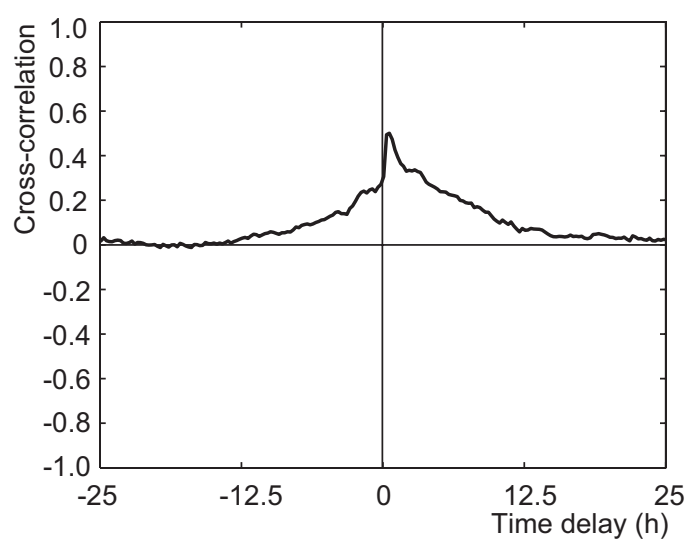

b) Orgnac near the Aven

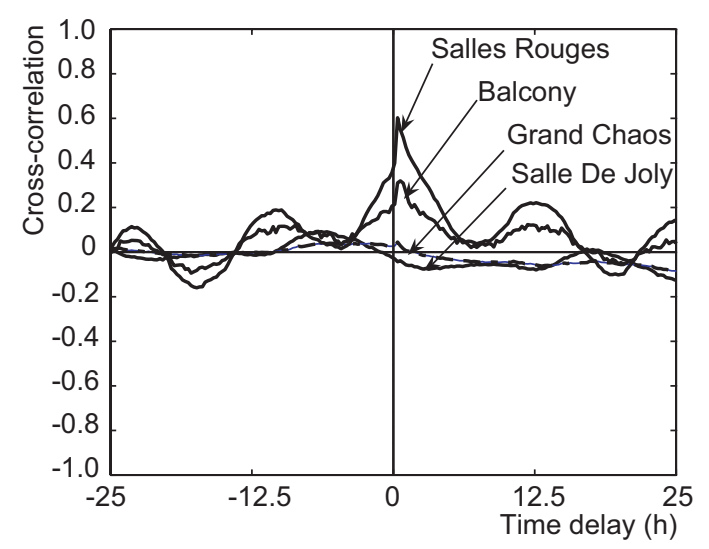

d) Chauvet

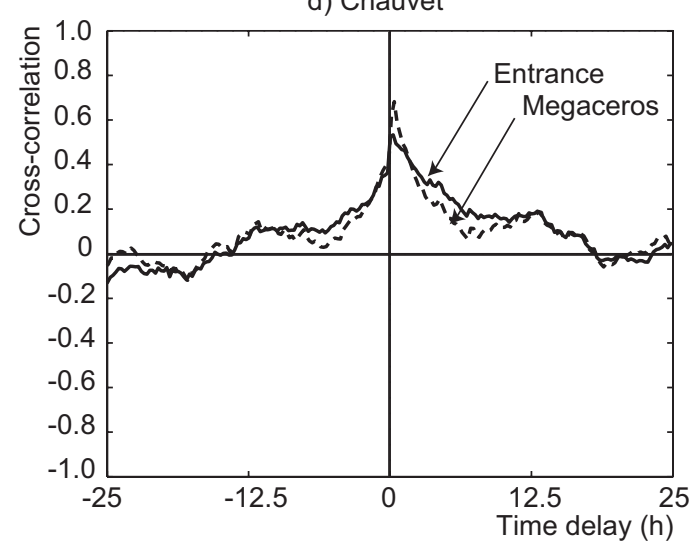

Figure 9 (Bourges et al.) 